\title{
Designing Causal Maps Adopting an Intellectual Capital Perspective: A Case Study Analysis
}

\author{
Federica De Santis (Corresponding author) \\ Dept. of Management, Università Politecnica delle Marche \\ 60121, Ancona, Italy \\ E-mail: f.desantis@univpm.it
}

Received: October 06, 2016 Accepted: November 01, 2016 Published: November 27, 2016

doi:10.5296/ijafr.v6i2.10119 URL: http://dx.doi.org/10.5296/ijafr.v6i2.10119

\begin{abstract}
Causal maps are a useful tool by which managers can understand what the key resources in their organization are and how these resources contribute to the value creation process. The aim of this paper is to understand, from an empirical perspective, if, how and why a causal map can be designed grounding on the Intellectual Capital (IC) studies. To achieve this aim a case study has been examined to reply to our research questions.

The contribution of this paper to the management accounting literature is twofold. First it suggests a method to improve causal maps by making visible two aspects, time and interconnections, that traditionally overlooked (Marr et al., 2004 Nørreklit, 2000). Second, it systematizes and extends the literature on how to account for time and on the relative importance of the temporal dimension in developing effective strategies.

The main findings of the research can be summed up as follows. From a methodological point of view, the use of multi-method approach in designing a causal map offers the opportunity to take into considerations the intensity of the relations and the time lag between activities and effects. Adopting an IC perspective, it emerges that the properties of IC (i.e. connectivity, dynamicity and specificity) have a great impact on the map and the adoption of an IC perspective in designing causal maps may be useful to enrich this management tool and to better consider the specific properties of IC.
\end{abstract}

Keywords: Intellectual capital, Causal map, Time, Performance, Plan 


\section{Introduction}

Today "hyper competition" characterizes domestic and international markets (D"e Aveni, 1994; Sengupta, 2013) and consequently firms need to implement strategies that respond to market opportunities by exploiting their resources. Therefore, managers need to understand what the key resources in their organization are in a way to use them to create value. In order to understand how resources contribute to the value creation process causal maps may be adopted. A causal map is defined as a cognitive map useful to capture the judgements about the link between actions and outcome and consequently to understand the cause of some results (Abernethy, 2005; Kaplan and Norton, 2000). An example of this kind of map is the strategic map proposed by Kaplan and Norton (Kaplan and Norton, 1992) in which the financial perspective is considered as the effect generated by variations in the other three Balanced Scorecard perspectives (customers, processes and learning and growth). Concluding, causal maps are a relevant management tool useful to understand and allocate attention to the value creation process (Simons, 1990; Roberts, 2000; Mouritsen, et al., 2001).

The idea of simply mapping the value creation process by identifying cause-and-effect linkages seems to break down at least with reference to two specific aspects. First, referring to the Intellectual Capital field and to the resource based view of the firm, it emerges that firm resources are bundled together and thus co-influence linkages can be identified, i.e. a resource can be both cause and effect of another resource (Dierickx and Cool, 1989). Second, even though several studies show that time is a relevant managerial variable (Mouritsen and Bekke, 1999; Skoog, 2003), causal maps, such as the strategic maps proposed by Kaplan and Norton (2000) tend to do not take into account the temporal dimension even if it is implied in the definition of cause-and-effect relationships. In fact, the cause has to precede the effect in time (Nørreklit, 2000). Moreover, organizations must find means to leverage their available resources at specific points in time in relation with market opportunities in order to create organizational value (Simons, 1990). Finally, according to Roberts and Chaminade (2003) the development of the aforementioned interconnections between firm resources requires time, which then becomes a strategic variable that managers have to consider. In all, the mapbuilding process must take into account the existing interconnections among firm resources and the time lag between causes and effects.

Moving from the consideration that there are little empirical evidences about how to consider both time and interconnections in practice in a map-building process, and that there is a call for more action into management accounting studies, the aim of this qualitative study is to describe a useful approach to enrich the causal maps in a way that they can better visualize how and when resources interact to create value. We argue that a better understanding of value creation can then be used as the basis for validation as well as decision-making (Ittner et al., 2003). The investigation here proposed is based on an action research case study. In particular, the process followed to strike a new venture business five-year plan is analysed pointing out the method adopted to visualize interconnections and time lags between causes and effects. An alliance context was chosen because JVs can be seen as a temporal continuum of different activities (Parise and Sasson, 2002) and, moreover, in the case under investigation, to strike the business plan cause and effect relationship had to be considered. 
So in here time and linkages appear to be relevant and useful to achieve the goal of this paper.

The contribution of this paper to the management accounting literature is twofold. First it suggests a method to improve a tool - i.e. causal maps - by making visible two aspects, time and interconnections, that traditionally overlooked (Marr et al., 2004 Nørreklit, 2000). Second, it systematizes and extends the literature on how to account for time and on the relative importance of the temporal dimension in developing effective strategies.

The structure of the paper is outlined as follows. The next section provides a brief analysis of the literature useful to explore the gap under investigation. Then, a case study is described analysing the how IC has been considered to draw a business plan of a new venture. In the central part, an attempt will be made to make sense of the case findings and to develop the theoretical arguments of the study. Finally, some valuable insights will be extracted and systematized to draw some conclusions and to propose future research opportunities.

\section{Theoretical Background}

\subsection{Defining IC}

In analysing the literature, many theorists have stated that the IC issue is very scattered and fragmented because of the plethora of concepts, methods and tools that have been proposed over the last 10 years (Guthrie et al., 2001). The IC concept, scholars said, is not well understood and rarely it is defined in a clear manner. By way of example, we can find authors that make reference to IC as the system composed of all of the firm 's intangibles (Meritum, 2001); others which make reference to IC as "the sum of everything everybody in a company knows that gives it a competitive edge" (Stewart, 1997); others which consider IC as a combination of knowledge flows (Mouritsen et alii, 2001) or of connections between intangible resources (Roberts, 2000). Moreover, IC can be studied focusing on its resources (static approach) or by underlining the activities carried out to create and develop it (dynamic approach) (Meritum, 2001). This situation could be hindered by the IC phenomenon itself or, more exactly, by its complex nature. In fact, IC is not one-dimensional, but rather, multidimensional and heterogeneous, and its elements are held together by relations (Gröjer, 2001; Bukh et al., 2001; Mouritsen et al., 2001).

In this work, we refer to the IC concept suggested by the Meritum Guidelines (2002) that is to say that IC is the system composed of all of the firm 's intangibles. In abstract terms, this resource can be broken down into three categories: human, structural and relational capital. Human capital is composed of tacit knowledge, capabilities and competences owned by the employees. Structural capital is made up of structured knowledge in the form of patents, databases, procedures, etc. It also comprises "softer" elements such as organizational and managerial processes, the organizational structure, the company philosophy, etc. Lastly, relational capital encompasses the relations whom a company develops with the stakeholders (customers, suppliers, institutions, etc.).

IC, as well as intangibles, has several specific properties (Itami, 1987; Canibano and Garcia Ayuso, 2000; Gröjer, 2001; Guthrie, et al., 2001; Kaplan and Norton, 2001; Meritum, 2002; Chaminade and Roberts, 2003; Mouritsen and Larsen, 2005). In this work, we focus on three 


\section{MlMacrothink}

International Journal of Accounting and Financial Reporting

ISSN 2162-3082

2016, Vol. 6, No. 2

particular aspects, which are the ones that impact more on the design process of a causal map: connectivity, dynamicity and specificity. It is generally accepted that IC creates value through connection with the other firm resources: IC has not value by itself but it must be bundled with other resources to create value. For example, to put in action and extract value from new a technical competence it could be require the ownership of specific processes or equipment or software, etc. Thus, the value arises from linking IC with its firm context (Chaminade and Roberts, 2003).

Another aspect is that IC, as knowledge, which is its basic component, is dynamic and not static (Mouritsen, et al., 2001). More in depth, IC changes over time and this implies the need to move the attention to the activities carried out to create and develop IC (flow) instead on the variation of the IC value (stock) (Mouritsen, et al., 2001). Moreover, this aspect of the IC is also related to the previous one: if IC changes also the connections it develops with the other resources change as well as its contribution to the value creation process (Marr, et al., 2004; Cuganesan, 2005). Finally, the dynamic nature of IC seems also to imply that the tools used to analyse and measure become from "stable"1 to "unstable" (Meritum, 2002), that is to say that the IC resources, activities and connections should be periodically revised to guarantee the same level of usefulness and maintain the rationality of the entire system.

The last IC property here discussed is its specificity. IC is firm specific and it depends on organizational context and strategy from at least two perspectives. The first is that IC, which is based on knowledge, cannot be created and/or replicated in the short term but only in a long term. This aspect limits strongly the possibility to have different contexts with the same IC (Itami, 1987). The second is that the IC value cannot be separated from the organizational processes that transform IC into financial results (Kaplan and Norton, 2001; Marr, et al., 2004). This aspect implies that the tools focused on IC cannot be generalized in all their aspects but, probably, only partly (structure, implementation process, etc.).

\subsection{Identifying and measuring cause-and-effect relations}

Building a causal map, such as the strategic one, is a means through which visualize the interrelations between actions and resources and between resources themselves, understand the value creation process and predicting the effect of certain actions (Kaplan and Norton, 2000). The main advantages generated by mapping the relations under analysis are represented by the possibility to clearly identify the actions needed to reach specific goals or to better understand the results achieved.

There is not a single method for eliciting causal maps in literature: in fact, they can be designed following statistical or qualitative methods (Abernethy, et al., 2005). The statistical methods are based on the analysis of data through statistical or computerized methods and consequently they are useful discover relations which are reliable and not purely subjective. The main withdraws of these models are related to the fact that the map proposed is the result of rules (subjectively) imposed by the users and that the interpretation of the results requires subjective evaluations. The qualitative methods are based, instead, on personal judgments and

\footnotetext{
${ }^{1}$ For the concepts of "stability" and "unstability", see (Burns, 2000; Granlund, 2001; Lukka, 2007).
} 
experiences of the managers and they allow for developing analyses even with not wide databases and "weighting" the relations found out. The main disadvantages are represented, instead, by the risk to focus on the most obvious links, to have incomplete analyses and/or identifying too complex maps. From these elements, it emerges that none of the aforementioned methods are able to grasp completely the complexities of the activities carried out and their relations: statistical methods are based on simplifications of the reality more or less relevant, while the other methods risk being too subjective.

Adopting the IC perspective in this mapping process implies considering how the IC concept impacts on the cause-and-effect relations from a theoretical point of view. The first aspect to consider is that IC generates value through the interaction among its components and with the tangible resources of the firm (Petty and Guthrie, 2000; Gröjer, 2001; Mouritsen, et al., 2001; Chaminade and Roberts, 2003). This implies that the argument of simply mapping performance drivers and outcomes (Kaplan and Norton, 2000) seems to break down when we take into account the interconnections between IC resources and tangible assets. Baruch Lev, for example, notes that "intangibles are frequently embedded in physical assets (e.g. the technology and knowledge contained in an airplane) and in labour (the tacit knowledge of employees), leading to considerable interactions between tangible and intangible assets in the creation of value" and "when such interactions are intense, the valuation of intangibles on a stand-alone basis becomes impossible" (Lev, 2001, p. 7). Focusing the attention on the interactions lead to monitoring not only the direct effect of an action but also the indirect ones and consequently it enriches the usefulness of the causal map (Marr, et al., 2004). We argue that mapping all the connections can guide to the design of a too complex map to be interpreted and applied in practice, also considering that this resource bundles impact on performance with causal ambiguity (Dierickx and Cool, 1989; Wilcox King and Zeithaml, 2001) and that IC components tend to transform each other often "in a pluralistic and fluid manner" (Cuganesan, 2005, p. 369). Thus, it becomes of interest to understand how these connections can be mapped and considered in practice, especially for planning purposes.

Another aspect to consider is the dynamicity of IC. Some studies have shown that IC changes over time as well as its contribution to the value creation process (Mouritsen, et al., 2001). Consequently, IC cannot be approached in a static way but in a dynamic one. The cause-andeffect relations, therefore, should not be stable but dynamic in terms both of existence and intensity. In other words, considering that generating a connection between IC components requires time (Chaminade and Roberts, 2003), it implies that over time new connection may arise and their intensity may vary, decreasing or increasing. This means that, from a longitudinal point of view, causal maps cannot be fixed but instead they should be periodically revised to keep into account not only the strategic changes (Kaplan and Norton, 2000) but also and especially the IC changes.

The last aspect here considered is the specificity of IC, that is to say that a firms ${ }^{\text {ee }} \mathrm{IC}$ is unique with reference to its components and its contribution to the value creation process. More in depth, the fact that IC is firm specific implies that the relations and their properties are strictly related to the context in which they are identified and that it is extremely difficult to replicate them in different environments. This consideration lead to the conclusion that also the causal 


\section{Mll Macrothink}

International Journal of Accounting and Financial Reporting

ISSN 2162-3082 2016, Vol. 6, No. 2

maps are firm specific and that it is not possible to define a general map or transfer and existing map to another context. Investigating how to realize a "map transfer" is not interesting only as a mere scientific exercise but also and especially to understand if and how a successful formula can be applied in practice in different firms or if and how an existing map can support the development of a plan of a new firm.

\subsection{Cause-and-effect relations and the time lag from an IC perspective}

Analysing the concept of "cause-and-effect", which is the core of this map, it emerges that, although it is not unanimously defined, most scientists and theories of science adopt Hume's criteria for a cause-and-effect relation (Nørreklit, 2000; Malina, et al., 2007). The criteria are (a) independence, (b) time precedence, and (c) predictive ability. The independence criterion states that events $\mathrm{X}$ (the cause) and $\mathrm{Y}$ (the effect) are logically independent. Furthermore, one cannot logically infer $\mathrm{Y}$ from $\mathrm{X}$ but only can do so empirically. The time-precedence criterion states that $\mathrm{X}$ precedes $\mathrm{Y}$ in time, and the two events can be observed close to each other in time and space. The predictive-ability criterion is that observation of an event $\mathrm{X}$ necessarily implies the subsequent observation of the other event Y. Albeit the existence of cause-andeffect relations in firms have been criticized by part of the literature (Nørreklit, 2000), they are of help to managers in evaluating ex ante or ex post the effects of their activities (Kaplan and Norton, 1996b) and in understanding and allocating attention to the value creation process (Simons, 1990; Roberts, 2000; Mouritsen, et al., 2001).

Generating value through the development of activities and the creation of connections among resources requires time, which is a basic element of a cause-and-effect relationship. As aforementioned, this kind of relations in fact assumes that an event (the cause) precedes another (the effect) in time. So considering time in the mapping process is useful to understand not if but when an action will produce the expected outcome.

Regarding the concept of time, Huy (Huy, 2001) identifies two differentiated understandings of time: quantitative and qualitative. Quantitative time is "clock time" which progresses linearly and is subject to a unitary interpretation and thus it can be considered as a "general time". Qualitative time, instead, is "slow time" in which personal and subjective experience has a primary role and thus this one can be considered as a "context-specific time". Applied to the field of management, some argues the notion of quantitative time is related to activities directly attached and managed toward time set targets and objectives while the qualitative time would be more closely linked to management control activities that take into account how other parts of the organization may be affected and how the activity fits into the present internal and external organizational situation (Skoog, 2003).

In the IC issue and also in the investigation of the link between IC performance and financial performance time seems to be particularly important for several reasons. First, IC requires time to be created and developed and to generate value (Chaminade and Roberts, 2003). Second, timing is also relevant if we think about selecting the appropriate moment for an activity. In planning the managerial activity to be carried out to create and develop a specific IC component, management has to take into consideration the temporal dimension and the existing natural temporal lag between the cause (the activity) and the effect (the 


\section{Mll Macrothink}

International Journal of Accounting and Financial Reporting

ISSN 2162-3082

2016, Vol. 6, No. 2

creation/development of the IC item) (Mouritsen, et al., 2001). Third, IC can be studied with a static approach, stressing the resources it is made of, or as a process, focusing on its dynamic aspects (Meritum, 2002). Forth, time is a relevant managerial variable (Mouritsen and Bekke, 1999; Nørreklit, 2000; Skoog, 2003; Quattrone and Hopper, 2005) and consequently in managing a strategic resource such as IC this dimension has to be considered.

These elements lead to the consideration that the analysis of IC with a temporal lens (Ancona, et al., 2001) allows also to achieve a clear representation on the temporal axis of the financial effects generated by IC activities (Roos, et al., 1998). In fact, the method and tools applied during the analysis should support the identification of the benefits that it generates not only on a quantitative and qualitative level but also at a temporal one that means representing the income in the right temporal coordinates (Lev and Zarowin, 1999). All in all, time has to be taken into account to bridge the gap between IC performance and financial performance and to define the cause-and-effect relationships among these two items. Albeit from a theoretical perspective there is not a generally accepted management accounting system time-compliant, it seems interesting to investigate if and how firms, in practice, consider this variable in mapping processes as well as how they estimate the time lag.

\section{Design of the Study}

In this paper we examine the ALPHA case study, which is interesting because it allows the analyses of the process empirically followed to design a causal map centred on IC from a longitudinal perspective, considering that the link between IC and financial performance has been investigated with reference to five years. Moreover the case study research design was considered appropriate given its capacity both for being a potentially rich and valuable source of "rich data" and for exploring relationships between variables in their given context (Yin, 2003). Thus, given the exploratory nature of this research and the need to obtain rich data, a case study approach was adopted; more precisely, the case study was undertaken using an "action research" methodology.

Action research involves a spiral of cycles of planning, acting, observing and reflecting and it is based on a collaborative problem-solving relationship between the researcher and client which aims at both solving a problem and generating new knowledge. In other words, the aim of action research is to try and make a difference to a situation. It typically involves examining practices and trying out ways of improving them (Coghlan and Brannick, 2001; Coghlan and Coghlan, 2002). This means that research needs to be purposeful and focused, not just information gathering. It is usually small-scale research that is intended to help researchers or practitioners in taking actions that are planned to make a difference and whose impact will be evaluated. In addition, action research differs mainly from other forms of applied research because of its explicit focus on action, that it to say that it is participative and requires a tight cooperation between the researchers and the firm's personnel involved in the project (Olesen and Myers, 1999) and, moreover, it aims to bridge the theory-practice gap (Cardno and Piggot-Irvine, 1996).

An action research approach was adopted to investigate the case under analysis for the 


\section{MInstitute Macrothink $_{\text {Int }}$}

International Journal of Accounting and Financial Reporting

ISSN 2162-3082

2016, Vol. 6, No. 2

following reasons. This approach allows to develop jointly scientific research and innovative practical solution for the firm (theoretically challenging and practically relevant) (Kaplan, 1998). The aim to develop a practical and tailor made solution let me open the door of the firm and consequently I could act as an insider (or as a "friendly outsider"). Consequently I had access to the organization and to its "rich" data whilst, as an outsider, it would have been difficult or even impossible (Labro and Tuomela, 2003), mainly considering that the most valuable IC information (e.g. the ones related to the development of particular competences, or to the actions carried out to create or develop customer relationships, or the design or production processes, etc.) are usually secret and not disclosed by firms. Finally, this method was chosen because it allows, more then other case-study approaches, to have frequent contacts with the firm and, consequently, to acquire a deeper knowledge and further insights and to remain focused on the research issue (Middel, et al., 2006). With specific reference to the accounting and the IC fields, the choice of an action research methodology was also due to the fact that there have been calls for the greater use and acceptance of action research techniques in accounting in general (Baker, 2000) and in the IC field in particular. several scholars, indeed, call for empirical IC analyses carried out trying to make the IC issue clearer also through the test of the plethora of theoretical theories and frameworks and through the development of practical micro-level analyses (Marr, et al., 2003).

The case under investigation, developed during 2015, is referred to a firm (ALPHA) which was going to fund a new venture (Newco) together with a partner. The researcher took part in the strategic focus group formed by the CEO, the CFO, the marketing director and the controller of ALPHA. The aim of the focus group was mainly to draw a reliable financial plan of the new venture and, on the basis of the Newco's forecast results, to determine the value of the contributions of the partners. Six groups meeting of, on average, 3 hours each were held in addition to some personal interviews done by the researcher with the single components of the group and some employees of the firm.

The focus group drew the plan together with ALPHA's partner. The agreement about the hypotheses adopted, the process and the final result was reached after several written (letters, e-mails, etc.) and verbal (phone call and meetings) contacts. Thus, the plan was discussed and shared in all its elements. The focus group meetings were based on a semi-structured agenda proposed by the researcher. More in depth, the researcher was of help in the arrangement and classification of the resources provided by the focus group and considered necessary by the New venture to develop its business. The classification was done referring to the following categories (Meritum, 2002): human capital, relational capital, structural capital and financial capital. After the mapping step, the researcher supported the management in the strike of the plan, that is to say, in coordinating and supporting the discussions. Moving from the analysis of the firm's archives and databases and from the past experiences of the single managers of ALPHA, the focus group, methodologically supported by the researcher, discussed and defined the activities to develop in each of the year examined to achieve the expected IC and financial performances. In other words, moving from the firm resource portfolio, the focus group defined the activities to carry out in order to transfer/create the IC in the new company and to activate it. After, the group identified the IC performance and its effects mainly 
expressed with non-financial indicators (e.g. reduction of wastes or error, development of new customer relationships, etc.). Moving from these indications, the costs related to the activities (e.g. training or marketing costs) together with the financial values of their effects (e.g. cost-reduction or extra sales) have been estimated.

All in all, the active researcher was involved in the case study but in a particular way. In fact, he did not act to supply practical solutions as a consultant but instead his activity consisted in a scientific and methodological support and in organizing the agenda of the group meetings. This means that the facts and the results described here below were not changed or influenced radically by the researcher and consequently the work can be defined as "scientific" (Kaplan, $1998)^{2}$.

\section{The Case Study}

ALPHA is a European player in the field of integrated solutions for plastic materials and injection moulds (turnover Euro $17 \mathrm{mln}$; 130 employees). In 2005, ALPHA decided to fund a new firm, here called Newco, together with a partner to develop new business relationships with potential foreign customers and suppliers of labour and raw materials to realize products at a lower cost (and consequently at a lower price) and consequently being able to penetrate new markets. In this Newco ALPHA was the main contributor of IC while the partner contributed almost exclusively with tangible assets. The researcher was involved in the process related to the striking of a five-year business plan.

The first step was the identification of the resources needed by Newco. As aforementioned, the tangible and IC resources needed by the firm have been identified by the management of ALPHA and its partner, considering their personal experience. During the identification process, the interconnections between resources had to be considered in order to avoid the risk to transfer resources and after not being able to use them effectively and efficiently. In way of example, to use the database containing all the past projects of the firm, specific competences, software and equipment were necessary respectively to interpret the information supplied, to run the database and to translate the technical information into the final product. Transferring the database without one of these other items would imply the impossibility to use it or, at least, the impossibility of an efficient and effective usage (e.g. different final results, more wastes, quality problems, etc.). The problem in this phase was that, albeit everything seemed to be linked, the strongest links had to be identified considering that it was impossible to transfer and recreate in the Newco all the ALPHA and partner's resources (e.g. it is not possible to transfer all the Human Capital). So, instead of considering the single resources, we focused on small groups of them defined by the focus group. In the following table the resources identified by the management and classified by the

\footnotetext{
${ }^{2}$ Kaplan (1998) highlights that a sort of action research, where researchers do manipulate the environment, on the base of experiments and theories, to create something new can be identified also in the physical and social sciences and thus the fact of the influence of the researcher on the case study cannot lead to declare a priori the work as non scientific.
} 
researcher following the Meritum Guidelines (Meritum, 2002) to achieve a clearer visualization are represented.

Table 1. Newco Resources

\begin{tabular}{|c|c|c|c|}
\hline Human Capital & Structural Capital & Relational Capital & Financial Capital \\
\hline $\begin{array}{l}\text {-Design } \\
\text { competences } \\
\text {-Production } \\
\text { competences } \\
\text {-Managerial } \\
\text { competences } \\
\text {... }\end{array}$ & $\begin{array}{l}\text {-Procedures } \\
\text {-Manuals } \\
\text {-Database } \\
\text {-Strategic Software } \\
\text {-Organizational } \\
\text { processes and } \\
\text { organizational } \\
\text { structure } \\
\ldots\end{array}$ & $\begin{array}{l}\text {-Image and } \\
\text { relationships of the } \\
\text { founders } \\
\text {-Relationships with } \\
\text { customers supplied } \\
\text { by the founders } \\
\text {-Relationships with } \\
\text { new customers } \\
\text { Relationships with } \\
\text { the institutions } \\
\text {... }\end{array}$ & $\begin{array}{l}\text {-Equipment } \\
\text {-Machineries } \\
\text {... }\end{array}$ \\
\hline
\end{tabular}

The Newco's resources identified by the management and classified by the researcher following the Meritum Guidelines

Moving from this resource portfolio, the management, supported by the researcher, started striking the business plan. The first step was the analysis of the how the Newco can enter in possess of these resources because each of different possible ways generates different, direct or indirect, financial effects. In particular, at first, for each resource have been defined whether it should have been conferred by the founders, bought on the market or internally generated by the Newco because of the diverse financial effect which corresponds to each of these alternatives. In way of example, the founders decided that the new venture has to buy on the market the equipment and to acquire the technical competences from ALPHA as capital contribution. In this discussion, it emerged that almost all the IC resource would have been transferred by the partners considering that they were firm-specific and consequently not available on the market.

Once the resource portfolio of the firm was defined, a causal map was designed in order to strike the plan of the Newco and consequently to link the activities of the partners and of the Newco's management with the financial performance. To define the map, the researcher and the group agreed in first mapping the cause-and-effect relations in ALPHA and then transfer and adapt the map to the Newco context. This decision had been taken for two main reasons. First, Newco, as a new entity, had no past data available and to base the analysis on a comparable context, such as ALPHA, was considered preferable rather than inventing subjectively all the information without a solid basis. Second, considering the relevance of IC for the success of the Newco and that ALPHA was the main contributor of IC, in ALPHA 


\section{Mll Macrothink}

International Journal of Accounting and Financial Reporting

ISSN 2162-3082

2016, Vol. 6, No. 2

several of the data necessary to design the map and strike the plan were available and useful to support the process. Operatively, to design the map, some focus groups meetings and semistructured interviews had been done together with the extraction, systematization, reclassification and sometimes elaboration (design and calculation of new indicators) of the data existing in the archives and databases. Through the matching between the results of the meetings and interviews and the analysis of the data collected it was possible to identify in an enough reliable way the links between the activities carried out, their impact on IC and on the firm performance and when this impact mainly took place. This multi-method approach, albeit proposed by the researcher mainly to limit the subjectivity naturally existing in the qualitative methods through the verification of the relations found out by the group (ex-post usefulness), was approved by the group also because the "hard" data was considered as a raw guide to design the map (ex-ante usefulness). The map designed with reference to the ALPHA context was then discussed with reference to the Newco context in terms of existence of the links, intensity and time dimension to strike the plan.

The process developed to draw the plan moving from the ALPHA's causal map was the following. First, the activities to carry out have been described analytically then the effects on the IC resources and on the firm performance have been quantified first with non financial indicators (e.g. quantity of time saved or reduction in wastes, errors etc.). Then, these effects have been expressed in financial terms (extra sales or cost reductions) making reference to some standard parameters determined analysing the ALPHA's archives (e.g. average cost of materials, standard salaries, etc.). This process was done with reference to each of the five years investigated. In other words, per each year considered the existence of the links, their intensity and the time required to transform an action into value were examined, discussed and estimated. In this discussion, on the one hand, the possible start-up problems and their impact on the relations were considered together with, on the other hand, the fact that moving from a past experience some actions would be carried out now more efficiently and effectively, avoiding mistakes or waste of time due to the uncertainty of the first time. Alas, positive and negative impact factors on the Newco performance were taken into consideration. The longitudinal analysis of the links was particularly interesting because it provided several evidences. In way of example, we noticed that the training of the third year was expected to generate an increase of production, in dependence of a time saving due to less mistakes, waste of time, etc., equal to 17.000 hours of work while the forth year, the same activity, would generate no increasing effect but only a maintenance effect, that is to say avoid the risk of a decrease. Therefore, it emerged that certain activities tend not to produce always their effects with the same entity. Moreover, it emerged that to put in action, and so to see the effect, of the first training more time was needed in comparison to put in action the new concepts taught in the following training sessions. So the case also highlighted a dynamicity of the time lag between activities and effects.

The final plan based on the valorisation of the activities and effect visualized in the five-year map designed moving from the aforementioned considerations had then been discussed again by the focus group and validated by the partner. 


\section{Findings and Conclusions}

Moving from the aforementioned case study, we try to highlight the interesting aspects, which can be useful for its interpretation and the analysis of similar stories. In particular, we will focus on some specific aspects that, we think, could contribute in general to the IC debate and, in particular, to deepen the understating of how causal maps are put in action in practice and how they can be enriched with the IC perspective.

The first aspect worth of notice is a methodological consideration. In the case study a multimethod approach have been applied, that is to say a method based on the combination of the focus groups discussions, interviews and analyses of data collected from the archives. The adoption of a multi-method approach seems to be, in fact, the most suitable way to ensure reliable maps (Abernethy, et al., 2005). The use of purely subjective methods risks leading to too subjective conclusions while the analysis of the archives only would imply the loss of some interesting aspects. Moreover, the case study contributes to the methodological debate with other three insights. The first is that in comparison with the work of Abernethy et al. (2005) the case shows how to combine qualitative and quantitative methods. In fact it emerges that the map elaborated with quantitative methods have a double validity, one ex ante, in supporting the discussions and interviews and consequently in being a rough map to be enriched through the qualitative methods, and one ex post, in being a means of testing the map subjectively designed. The analysis of which of the two possibilities proposed could be the best way to achieve the final result represent a future research opportunity. The second methodological contribution is represented by the fact that this multi-method approach appears to be profitable also to approach the time dimension that is rarely subject to specific investigation or discussion in empirical works (Mouritsen and Bekke, 1999; Skoog, 2003). The last contribution provided by the case study is related to the action research methods. Some argue that in developing action research project there is the risk to be too subjective in the way the researcher perceives the reality because he becomes an actor instead of simple outside observer of the process: consequently his reflections risk being not completely correct (Middel, et al., 2006). In order to mitigate this subjectivity Middel et al. (2006) suggest to ground the research on "hard" data as much as possible and consequently adopting multiple viewpoints. From this point of view, drawing a map through the abovementioned multimethod approach can be also seen a way for the researcher to guarantee a more scientifically rigorous result. Overall, the multi-method approach appears both scientifically and practically preferable in comparison to a single method approach.

The other aspects here discussed are related to how the IC perspective can enrich the design process of a causal map. This discussion will be centred considering the properties of IC described in the theoretical background: connectivity, dynamicity and specificity. Regarding the connectivity, moving from the case study, the connections between resources came up clearly from the focus group and the interviews both in the definition of the Newco $s$ resource portfolio and in designing the map. In the first case, it emerged the need to talk and focus the attention on groups of IC components instead of single items considering that they were able to generate value only in case of joint-presence in the context. In the second case, it emerged in terms of necessity to identify the links between IC components and between IC and the 


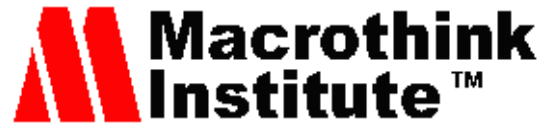

International Journal of Accounting and Financial Reporting ISSN 2162-3082 2016, Vol. 6, No. 2

other firm resources to have a complete visualization of the value creation process. This evidence confirms first the need to approach the firm resources in a systemic way, that is to say considering the existing bundles of resources in which the different resources depend on each other to create value, as stated by the Resource Based View (Wernerfelt, 1984; Barney, 1991; Grant, 1991; Barney, 2001). Second, it confirms empirically also the theories that IC do not generate by itself but only when put in relation with other resources and activated through specific actions (Roberts, 2000; Mouritsen, et al., 2001; Chaminade and Roberts, 2003). The case study, in addition to confirm empirically these theories, points out the opportunity to integrate the causal map design process taking into consideration the IC connections, that is to say considering not only the direct but also the indirect effect of an IC action. In practice, this means that in designing a map the focus should move from the single leading items to leading groups of items. From a practical perspective, considering that all the firm resources are more or less interrelated, visualizing all the connections can be problematic. Thus, the attention should be focused only on the more intense (relevant) connections as to have a clearer map able to guide the managers and the employees of the firm.

The dynamicity of IC (Mouritsen, et al., 2001) seems to affect both the intensity of the connections and the temporal lag between actions and effects. In striking the five-year plan, it came into view that these two elements change over time, decreasing or increasing because of the other changes of the context and not in a linear way. This implies that mapping IC intensive firms can be a more complex process than the one referred to traditional companies. Moreover, this aspect involves also that map cannot be seen as a fixed tool useful to guide the management activity but as a dynamic one to revise periodically to take into account different intensity and different time lags. As aforementioned, the need, from a practical perspective, to visualize not all but only the more intense relations can lead to the design of different causal maps, with different connections showed, in dependence of the moment in which the context is observed.

The last aspect here examined is related to the fact that IC is firm specific. It comes clearly into view that the map designed with reference to the ALPHA's context was not considered reliable also for the Newco but it was modified in lots of its aspect such as links, their intensity and time lags. Consequently the evidences confirm that the IC contribution to the value creation process is not only dynamic but, instead, firm specific and consequently it is not possible to think about an analysis model generalizable in all its aspect (items, relations, etc.) (Abernethy, et al., 2005). It also shows that also the concept of time to use is not the general but the specific one, based on the personal experiences and it is strictly related to the context investigated (Nørreklit, 2000; Huy, 2001; Skoog, 2003).

All in all, it seems that the adoption of an IC perspective in designing and interpreting a causal map can be profitable to better highlight the specific properties of this resource. This perspective allows to better focus on the direct and indirect effect of the activities carried out and to keep in mind that map is a time and context specific tool.

\subsection{Conclusions}

The aim of this paper is to understand, from an empirical perspective, if, how and why a 
causal map can be designed grounding on the IC studies. To achieve this aim a case study has been examined to reply to our research questions. From the analysis of the evidences collected we can draw the following conclusions.

From a methodological point of view, the empiric analysed highlights the opportunity to adopt a multi-method approach to design the map and define the intensity of the relations and the time lags between activities and their effects. In fact, it appears to be useful to keep the positive aspects of the qualitative methods and mitigate their subjectivity in a way to obtain reliable results. The multi-method here examined consists in a combination of focus group discussions, semi-structured interviews and analyses of data extracted from the firm archives. In the discussion is also described how can be combined these different methods and the effect on the behaviour and on the results these different combinations can generate.

From an IC perspective, it emerges that the connectivity, dynamicity and specificity of IC influence in depth the map. The connections among IC components and between IC and the other firm resources have to be considered to achieve a complete visualization of the causal links and being able to consider all the direct and indirect effect of an action. In addition, it appears useful, from a practical purpose, to move the focus from single items to groups of items to visualize better the connections and have a clearer map. The dynamicity impacts on the existence, intensity and time lag between actions and effects and consequently implies the need to update periodically the map. Finally, the specificity relies to the fact that all the links are firm specific and consequently a map cannot be replicated in another context without adapting it. All in all, this study has highlighted that the adoption of the IC perspective in designing causal map can be useful to enrich this tool and to better consider the specific properties of IC.

The limitations of this study are twofold. The first are related to the particular research methodology adopted (action research) and the risks already highlighted to have influenced the reality and to have been too subjective in the analysis. We think that the specific activities developed by the researcher and already described together with the continuous matching between theory and practice in the analysis and the use, as much as possible, of hard data have considerably limited those risks. The second is that here the researcher examined a case study and thus the results cannot be immediately generalized. However, the object of this research study was not to define a design process to generalize but to highlight the specificities and the benefits, which potentially may come from designing a causal map from an IC perspective. We believe that these considerations can be generalized and discovered in other case studies too.

Future research opportunities are represented on empirical studies that may investigate the following items. The first item refers to the application of the multi-method approach here used in other contexts in order to reach a deep understanding of its potential and of the possibility to generalize it. The second research path is represented by the exam of the effects generated by a different order of combination of the qualitative and quantitative methods to map the cause-and-effect relations. Another research path is related to the analysis in other context of the interconnections between IC resources and IC and the other firm resources in 
order to understand if there are recurrent elements. Finally, it can be interesting to analyse how causal maps can be can be successfully integrated with IC methods and tools to enrich them both from a scientific and from a practical perspective.

\section{References}

Abernethy, M.A., Horne, M., Lillis, A.M., Malina, M.A. and Selto, F.H. (2005), "A multimethod approach to building causal performance maps from expert knowledge", Management Accounting Research, Vol. 16, No. 2, pp. 135-155.

Ancona, D.G., Goodman, P.S., Lawrence, B.S. and Tushman, M.L. (2001), "Time: A new research lens", Academy of Management Review, Vol. 26, No. 4, pp. 645-663.

Andriessen, D.G. and Stam, C.D. (2004), The Intellectual Capital of the European Union. Measuring the Lisbon agenda, Centre for Research in Intellectual Capital INHOLLAND University of professional education de Baak - Management Centre VNO-NCW,

Baker, C.R. (2000), "Towards the increased use of action research in accounting information systems", Accounting Forum, Vol. 24, No. 4, pp. 366-378.

Barney, J.B. (1991), "Firm resources and sustained competitive advantage", Journal of Management, Vol. 17, No. 1, pp. 99-120.

Barney, J.B. (2001), "Is the resource-based 'view' a useful perspective for strategic management research? Yes", Academy of Management Review, Vol. 26, No. 1, pp. 41-56.

Bourne, M., Mills, J., Wilcox, M., Neely, A. and Platts, K. (2000), "Designing, implementing and updating performance measurment systems", International Journal of Operation \& Production Management, Vol. 20, No. 7, pp. 754-771.

Brás, F.A. and Rodrigues, L.L. (2007), "Accounting for firms' training programs: an exploratory study", Journal of Human Resource Costing \& Accounting, Vol. 11, No. 3, pp. 229-250.

Bukh, P.N., Larsen, H.T., \& Mouritsen, J. (2001), "Constructing intellectual capital statements", Scandinavian journal of management, Vol. 17, No. 1, pp. 87-108.

Burns, J.a.S., R.W. (2000), "Conceptualizing management accounting change: an institutional framework", Management Accounting Research, Vol. 11, No. 1, pp. 3-25.

Canibano, L. and Garcia Ayuso, M. (2000), "Accounting for intangibles: a literature review", Journal of Accounting Literature, Vol. 19, No. pp. 102-130.

Cardno, C. and Piggot-Irvine, E. (1996), "Incorporating action research in school senior management training", International Journal of Educational Management, Vol. 10, No. 5, pp. $19-24$.

Chaminade, C. and Roberts, H. (2003), "What it means is what it does: a comparative analysis of implementing intellectual capital in Norway and Spain", European Accounting Review, Vol. 12, No. 4, pp. 733-751. 


\section{Ml Macrothink}

International Journal of Accounting and Financial Reporting

ISSN 2162-3082 2016, Vol. 6, No. 2

Coghlan, D. and Brannick, T. (2001), Doing Action Research in Your Own Organization, London.

Coghlan, P. and Coghlan, D. (2002), "Action research for operations management", International Journal of Operation \& Production Management, Vol. 22, No. 2, pp. 220-240.

Cuganesan, S. (2005), "Intellectual capital-in-action and value creation. A case study of knowledge transformation in an innovation process", Journal of Intellectual Capital, Vol. 6, No. 3, pp. 357-373.

D"Aveni, R. (1994), "Hypercompetition: Managing the dynamics of strategic management." New York.

DATI (2000), A Guideline for Intellectual Capital Statements: A Key to Knowledge Management, Danish Agency for Development of Trade and Industry

Dierickx, I. and Cool, K. (1989), "Asset Stock Accumulation and Sustainability of Competitive Advantage", Management Science, Vol. 35, No. 12, pp. 1504-1511.

Edvinsson, L. and Malone, M.S. (1997), Intellectual Capital, Harper Business, New York.

Granlund, M. (2001), "Towards explaining stability in and around management accounting systems", Management Accounting Research, Vol. 12, No. 2, pp. 141-166.

Grant, R.M. (1991), "The resource-based theory of competitive advantage: implications for strategy formulation", California Management Review, Vol. 33, No. 3, pp. 14-35.

Gröjer, J.E. (2001), "Intangibles and accounting classifications: in search of a classification strategy", Accounting, Organizations and Society, Vol. 26, No. 7, pp. 695-713.

Guthrie, J., Petty, R. and Johanson, U. (2001), "Sunrise in the knowledge economy: managing, measuring, and reporting intellectual capital", Accounting, Auditing \& Accountability Journal, Vol. 14, No. 4, pp. 365-384.

Huy, Q.N. (2001), "Time, temporal capitability and planned change", Academy of Management Review, Vol. 26, No. 4, pp. 601-623.

Itami, H. (1987), Mobilizing Invisible Assets, Harvard University Press, Cambridge, MA.

Ittner, C. D., Larcker, D. F., \& Randall, T. (2003). "Performance implications of strategic performance measurement in financial services firms", Accounting, Organizations and Society, Vol. 28, No. 7, pp. 715-741.

Kaplan, R.S. (1998), "Innovation Action Research: creating new management theory and practice", Journal of management accounting research, Vol. 10, No. pp. 89-118.

Kaplan, R.S. and Norton, D.P. (1992), "The Balanced Scorecard - Measures That Drive Performance", Harvard Business Review, Vol. 70, No. 1, pp. 71-79.

Kaplan, R.S. and Norton, D.P. (1996a), "Linking the balanced scorecard to strategy (Reprinted from the Balanced Scorecard)", California Management Review, Vol. 39, No. 1, 
pp. 53-\&.

Kaplan, R.S. and Norton, D.P. (1996b), "Using the balanced scorecard as a strategic management system", Harvard Business Review, Vol. 74, No. 1, pp. 75-\&.

Kaplan, R.S. and Norton, D.P. (2000), "Having trouble with your strategy? Then map it", Harvard Business Review, Vol. 78, No. 5, pp. 167-+.

Kaplan, R.S. and Norton, D.P. (2001), "Transforming the Balanced Scorecard from Performance Measurement to Strategic Management: Part I", Accounting horizons, Vol. 15, No. 1, pp. 87-104.

Labro, E. and Tuomela, T.S. (2003), "On bringing more action into management accounting research: process considerations based on two constructive case studies", European Accounting Review, Vol. 12, No. 3, pp. 409-442.

Lev, B. (2001), Intangibles: Management, Measurement and Reporting, Washington D.C.

Lev, B. and Zarowin, P. (1999), "The boundaries of financial reporting and how to extend them", Journal of Accounting Research, Vol. 37, No. 2, pp. 353-385.

Lukka, K. (2007), "Management accounting change and stability: loosely coupled rules and routines action", Management Accounting Research, Vol. 18, No. 1, pp. 76-101.

Malina, M.A., Nørreklit, H. and Selto, F.H. (2007), "Relations among Measures, Climate of Control, and Performance Measurement Models", Contemporary accounting research, Vol. 24, No. 3, pp. 935-982.

Marr, B. and Chatzkel, J. (2004), "Intellectual capital at the crossroads", Journal of Intellectual Capital, Vol. 5, No. 2, pp. 224-229.

Marr, B., Gray, D. and Neely, A. (2003), "Why do firms measure their intellectual capital?" Journal of Intellectual Capital, Vol. 4, No. 4, pp. 441-464.

Marr, B., Schiuma, G. and Neely, A. (2004), "The dynamics of value creation: mapping your intellectual performance drivers", Journal of Intellectual Capital, Vol. 5, No. 2, pp. 224-229.

Meritum (2002), Proyecto Meritum: guidelines for managing and reporting intangibles, Madrid.

Middel, R., Coghlan, D., Coghlan, P., Brennan, L. and McNichols, T. (2006), "Action research in collaborative improvement", International Journal of Technology Management, Vol. 33, No. 1, pp. 67-91.

Mouritsen, J. and Bekke, A. (1999), "A space for time: accounting and time based management in a high technology company", Management Accounting Research, Vol. 10, No. 2, pp. 159-180.

Mouritsen, J. and Larsen, H.T. (2005), "The 2nd wave of knowledge management: The management control of knowledge resources through intellectual capital information", Management Accounting Research, Vol. 16, No. pp. 371-394. 


\section{Macrothink}

International Journal of Accounting and Financial Reporting

ISSN 2162-3082

2016, Vol. 6, No. 2

Mouritsen, J., Larsen, H.T. and Bukh, P.N.D. (2001), "Intellectual capital and the 'capable firm': narrating, visualising and numbering for managing knowledge", Accounting Organizations and Society, Vol. 26, No. 7-8, pp. 735-762.

Nørreklit, H. (2000), "The balance on the balanced scorecard - a critical analysis of some of its assumptions", Management Accounting Research, Vol. 11, No. pp. 65-88.

Olesen, K. and Myers, M.D. (1999), "Trying to improve communication and collaboration with information technology: an action research project which failed", Information Technology \& People, Vol. 12, No. 4, pp. 317-332.

Petty, R. and Guthrie, J. (2000), "Intellectual capital literature review, measuring, reporting and management", Journal of Intellectual Capital, Vol. 1, No. 2, pp. 155-176.

Pike, R.H., Roos, G. and Marr, B. (2005), "Strategic management of intangible assets and value drivers in R\&D organizations", R\&D Management, Vol. 35, No. 2, pp. 111-124.

Parise, S., \& Sasson, L. (2002), "Leveraging knowledge management across strategic alliances", Ivey Business Journal, Vol. 66, No. 4, pp. 41-47.

Quattrone, P. and Hopper, T. (2005), "A ,time-space odyssey" : management control systems in two multinational organisations", Accounting, Organization and Society, Vol. 30, No. 7-8, pp. 735-764.

Roberts, H. (2000), "Classification of intellectual capital", in G. HEC, Classification of Intangibles, Jouy-en-Josas, 197-205.

Roos, G., Roos, J., Dragonetti, N. and Edvinsson, L. (1998), Intellectual Capital: navigating in the new business landscape, New York University Press, New York.

Roslender, R. and Fincham, R. (2001), "Thinking critically about intellectual capital accounting", Accounting, Auditing \& Accountability Journal, Vol. 14, No. 4, pp. 383-398.

Roslender, R. and Fincham, R. (2004), "Intellectual capital accounting in the UK: A field study perspective", Accounting, Auditing \& Accountability Journal, Vol. 17, No. 2, pp. 178 209.

Sengupta, J. (2013), "Theory of innovation: a new paradigm of growth", Springer Science \& Business Media.

Simons, R. (1990), "The role of management control systems in creating competitive advantage: new perspectives", Accounting, Organizations and Society, Vol. 15, No. 1/2, pp. 127-143.

Skoog, M. (2003), "Visualising value creation through the management control of intangibles", Journal of Intellectual Capital, Vol. 4, No. 4, pp. 487-504.

Sveiby, K.E. (1997), "The Intangible Assets Monitor", Journal of Human Resource Costing \& Accounting, Vol. 2, No. 1, pp. 73-97.

Wernerfelt, B. (1984), "A resource-based view of the firm", Strategic Management Journal, 


\section{Macrothink \\ International Journal of Accounting and Financial Reporting \\ ISSN 2162-3082}

Vol. 5, No. 3, pp. 171-180.

Wilcox King, A. and Zeithaml, C.P. (2001), "Competencies and firm performance: examining the causal ambiguity paradox", Strategic Management Journal, Vol. 2, No. 1, pp. 75 - 99.

Yin, R.K. (2003), Case study research: Design and Methods, 3/e, Sage Publications, Newbury Park.

\section{Copyright Disclaimer}

Copyright for this article is retained by the author(s), with first publication rights granted to the journal.

This is an open-access article distributed under the terms and conditions of the Creative Commons Attribution license (http://creativecommons.org/licenses/by/3.0/). 